\title{
A FAMÍLIA NA HISTÓRIA DAS POLÍtTICAS DE ATENÇÃO EM SAÚDE MENTAL: UM ESTUDO DOCUMENTAL
}

\author{
Maíra Bonafé Sei \\ Universidade Estadual de Londrina \\ Eneida Santiago \\ Universidade Estadual de Londrina
}

\begin{abstract}
Resumo
Neste artigo é feito o delineamento e problematização da instituição familiar como coadjuvante dos processos de cuidado do sujeito em sofrimento psíquico. Tal percurso foi realizado a partir da cartografia de legislações brasileiras que trataram diretamente da assistência e da atenção em saúde e em saúde mental, políticas que consideramos como produtos e produtores de agenciamentos sociais, políticos e científicos, configurando discursos postos como verdades naqueles momentos. Os documentos discutidos foram a primeira legislação brasileira de assistência psiquiátrica de 1903, um segundo decreto de 1934 e a Lei da Reforma Psiquiátrica de 2001. Concomitante, foi realizada uma revisão sobre estudos que articularam família e atenção em saúde mental. Ao final, indicamos que a noção de família está presente na história das políticas de atenção em saúde mental, mas com posições e funções jurídicas e terapêuticas distintas, dependendo do contexto histórico considerado, sendo atravessada por vieses de gênero, raça e características socioeconômicas. Além disso, notamos que o chamado e a presença da família na assistência e no cuidado com o sujeito em sofrimento psíquico assumiram formas coincidentes ou aproximadas com as transformações que a própria instituição familiar vivenciou nas últimas décadas.
\end{abstract}

Palavras-chave: família; saúde pública; reforma psiquiátrica; política pública; legislação em saúde.

\section{THE FAMILY IN THE HISTORY OF MENTAL HEALTH CARE POLICIES: A DOCUMENTARY STUDY}

\begin{abstract}
In this article the delineation and problematization of the family institution is done as supporting the care processes of the subject in psychological distress. This course was based on the cartography of Brazilian legislation that dealt directly with health and mental health care and attention, policies that we consider as products and producers of social, political and scientific agencies, configuring discourses as truths in those moments. The documents discussed were the first Brazilian psychiatric care legislation of 1903, a second decree of 1934 and the Psychiatric Reform Law of 2001. At the same time, a review was conducted on studies that linked family and mental health care. In the end, we indicate that the notion of family is present in the history of mental health care policies, but with different legal and therapeutic positions and functions, depending on the historical context considered, being crossed by biases of gender, race and socioeconomic characteristics. In addition, we note that the call and the presence of the family in the care and care of the subject in psychological distress took on forms coincident or approximate with the transformations that the family institution itself has experienced in recent decades.
\end{abstract}

Keywords: family; public health; psychiatric reform; public policy; health legislation. 


\title{
FAMILIA EN LA HISTORIA DE LAS POLÍTICAS DE CUIDADO DE LA SALUD MENTAL: UN ESTUDIO DOCUMENTAL
}

\begin{abstract}
Resumen
En este artículo, la delimitación y problematización de la institución familiar se realiza como apoyo a los procesos de atención del sujeto en angustia psicológica. Este curso se basó en la cartografía de las legislaciones brasileñas que trataban directamente con la atención y atención de salud y salud mental, políticas que consideramos como productos y productores de agencias sociales, políticas y científicas, configurando discursos como verdades en esos momentos. Los documentos discutidos fueron la primera legislación brasileña de atención psiquiátrica de 1903, un segundo decreto de 1934 y la Ley de reforma psiquiátrica de 2001. Al mismo tiempo, se realizó una revisión de estudios que vinculaban la atención de la salud familiar y mental. Al final, indicamos que la noción de familia está presente en la historia de las políticas de atención de salud mental, pero con diferentes posiciones y funciones legales y terapéuticas, dependiendo del contexto histórico considerado, atravesadas por sesgos de género, raza y características socio-económicas. Además, observamos que el llamado y la presencia de la familia en el cuidado y el cuidado del sujeto en angustia psicológica tomó formas coincidentes o aproximadas con las transformaciones que la institución familiar misma ha experimentado en las últimas décadas.
\end{abstract}

Palabras clave: familia; salud pública; reforma psiquiátrica; política pública; legislación sanitaria.

\section{INTRODUÇÃO}

Uma história da loucura é uma história dos discursos edificados sobre este fenômeno. Foucault (2014) defende que para o estudo da afirmação da loucura como doença mental não se deve ficar restrito ao âmbito da medicina ou de outras áreas biomédicas. Precisa ser considerada, também, a alienação jurídica como elemento interferente da experiência de ser sujeito, vindo a tornar este um indivíduo incapaz.

Ao longo da história da assistência e cuidado em saúde mental, a temática "família" está onipresente. Tem-se desde uma compreensão da instituição familiar como instância potencialmente desestabilizadora de famílias com características e (des)arranjos particulares até a compreensão deste núcleo como espaço privilegiado de recuperação e/ou manutenção da normalidade de indivíduos outrora adoecidos (Pegoraro, 2009; Santin \& Klafke, 2011).

Com isso, entende-se ser possível traçar uma história das políticas de assistência e atenção em saúde mental em determinada especificidade: aquela que delineia e problematiza a instituição familiar como coadjuvante dos modos de cuidar do sujeito adoecido mentalmente. Esta outra história sustenta-se na compreensão de que o que se denomina por loucura é um vasto, complexo e polissêmico campo teórico-prático composto por saberes sociais, históricos, culturais e juridicamente construídos e sustentados.

Desta forma, fazemos o delineamento e a problematização da instituição familiar como coadjuvante dos processos de cuidado do sujeito em sofrimento psíquico. Tal percurso é realizado a partir da cartografia de legislações brasileiras que trataram diretamente da assistência e da atenção em saúde e em saúde mental, políticas que consideramos como produtos e produtoras de 
agenciamentos sociais, políticos e científicos, configurando discursos postos como verdades naqueles momentos. Os documentos cartografados e colocados em diálogo com estudos do campo da saúde mental e coletiva foram a primeira legislação brasileira de assistência psiquiátrica (Decreto n. 1.132, 1903), um segundo texto da década de 1930 (Decreto n. 24.559, 1934) e a Lei da Reforma Psiquiátrica (Lei Federal n. 10.216, 2001). Concomitantemente, foi realizada uma revisão sobre estudos que articularam família e atenção em saúde mental.

Contudo, antes de iniciar esse percurso, cabe discorrer brevemente sobre a conceituação de família. Apesar de Meyer (2002) definir família como "uma unidade sócio-econômica organizada em torno de um par heterossexual, ou seja, um par potencialmente capaz de reproduzir a referida unidade" (p. 9), entendese que, como posto por Berenstein (1988), "a variedade de relações familiares é grande e ocorre de acordo com algum, ou até de vários, modelos de organização familiar" (p. 28). Tal autor questiona o que desejamos dizer quando nos referimos ao "grupo familiar" e retoma definições sociológicas, antropológicas e psicológicas do ser família (Berenstein, 1988).

Em consonância com a ideia de que são possíveis diferentes formas de ser família, tem-se, na atualidade, a presença mais constante de famílias homoparentais constituídas pela via biológica, haja vista as tecnologias no campo da reprodução assistida (Pontes, Féres-Carneiro, \& Magalhães, 2015) ou por meio da adoção (Silva, Sousa, \& Fernandes-Eloi, 2017), inclusive, casais sem filhos por opção (Silva \& Frizzo, 2014), com mudanças que demandam uma reinvenção da família (Roudinesco, 2003). Além da organização familiar em si, pode-se pensar na função desempenhada pelos demais parentes, amigos, vizinhos no caso das famílias de classes populares, que acabam por estabelecer uma rede de solidariedade, lembrando da maior vulnerabilidade dessas famílias diante do adoecimento mental de um dos familiares, haja vista a redução dos rendimentos e os conflitos gerados entre seus membros e entre eles e o domínio público (Souza, Pereira, \& Scatena, 2002).

Torna-se importante, nas discussões deste texto, considerar as transformações do conceito de família, nos distintos contextos históricos. Desta forma, a hipótese que defendemos é de que os textos legais, sobre os quais nos debruçamos, são exemplos de operadores jurídicos na área de saúde mental de tais reconfigurações conceituais.

\section{DESENHO METODOLÓGICO}

Trata-se de um estudo teórico, de caráter documental, que visa discutir conceitos e dados históricos sobre o lugar da família no campo das políticas de atenção em saúde mental a partir das proposições da legislação brasileira. Os documentos selecionados foram os textos legislativos de assistência psiquiátrica no fim da Primeira República até a atual Política Nacional de Saúde Mental, 
aprovada em 2001. Tais escritos oficiais são colocados em diálogo com produções científico-acadêmicas tanto da área de saúde mental quanto dos estudos de família.

O período abarcado foi definido por concentrar três ocorrências que se colocam como fundamentais para esta discussão: em 1903, momento da promulgação da primeira legislação de assistência psiquiátrica brasileira que será revogada em 1934; a aprovação de um segundo documento jurídico em 1934, que ficará em vigor até o ano de 1990; a lei que constitui o Sistema Único de Saúde (SUS), de 1990, no qual a atual Política Nacional de Saúde Mental, instituída em 2001 irá se ancorar.

A perspectiva metodológica aqui utilizada foi a qualitativa, com assinalações pautadas na cartografia que percorreu a pesquisa documental como estratégia investigativa. A cartografia não é exatamente um método em si, mas uma discussão metodológica acerca dos caminhos e dos encontros do pesquisador com os territórios cartografados, podendo ser estes territórios subjetivos e psicossociais (Rolnik, 2006). A tarefa de cartografar pressupõe a valorização dos sentidos e das histórias que mobilizam afetos e produzem realidades a partir de (re)configurações da vida social e, portanto, também subjetiva. Desta forma, a cartografia "... é uma prática de pesquisa que acompanha o processo de produção de subjetividade." (Rolnik, 2006, p. 21).

Enquanto objetivo central, apreendemos a história da atenção em saúde mental brasileira, na qual fazemos um recorte do conceito "família" buscando, assim, localizar e problematizar a maneira como a legislação brasileira contempla o núcleo familiar como parte do processo de assistência e atenção ao indivíduo considerado doente mental. Em consonância com o objetivo principal, discutimos qual o conceito de família utilizado nas políticas em questão; que rupturas estes conceitos operam com os conceitos anteriores e que atualizações delas foram produzidas; que configurações de estratégias de assistência e atenção em saúde mental o conceito de família compõe; e, por fim, que arranjos políticos, jurídicos e subjetivos emergiram como efeitos da produção desses dispositivos.

Torna-se importante a diferenciação quanto aos termos utilizados quando nos referimos aos princípios das legislações: ora colocamos "assistência" ora "atenção". A partir de uma coerência teórica e por entendermos que as palavras elencadas para um texto remetem às construções históricas, a escolha de uso de um termo ou outro não é aleatória. Sustentamos nossas escolhas nas discussões de Costa-Rosa (2000) sobre a distinção entre o modo asilar e sua oposição, o modo psicossocial enquanto configuração de saberes e práticas no campo da saúde mental e coletiva. 


\section{RESULTADOS}

A apreciação da história da legislação brasileira de atenção em saúde mental permite a formulação de questionamentos a partir de perspectivas subjetivas, sociais, históricas e políticas quanto a que anseios e objetivos o cuidado construído, ou não construído, responderia. Estes questionamentos referem-se ao tema "doença", ao sujeito considerado "doente" e, como categoria privilegiada nesta discussão, a terapêutica "família", entendendo-a como o núcleo ou laços familiares, tendo-se notado que a família era demandada como responsável ou principal articuladora de procedimentos de tratamento e cura daqueles em sofrimento psíquico.

\section{A psiquiatrização da loucura}

A primeira lei geral brasileira de assistência aos doentes mentais foi o Decreto 1.132, de 22 de dezembro de 1903 que definiu a reorganização da assistência aos alienados (Decreto 1.132, 1903). Tal decreto foi de iniciativa e redação de João Carlos Teixeira Brandão, psiquiatra e deputado federal que se candidatou com uma plataforma voltada para questões envolvendo a doença mental, partindo de uma compreensão compatível com os saberes hegemônicos na psiquiatria da época. Desta forma, a história do redator do decreto é tão importante quanto o próprio decreto.

Teixeira Brandão formou-se médico no Rio de Janeiro e fez estudos e estágios de formação em psiquiatria, na época chamada de medicina mental, na França, Alemanha e Itália, por volta dos anos de 1870-1880, tornando-se alienista, termo atribuído ao médico psiquiatra, à época. No Brasil, ocupou a primeira cadeira de Clínica Psiquiátrica e Moléstias Nervosas, criada no país na Faculdade de Medicina do Rio de Janeiro, atual Universidade Federal do Rio de Janeiro. Ocupou diversas posições no Hospício Pedro II, o primeiro hospital psiquiátrico brasileiro, onde promoveu questionamentos sobre a estrutura institucional e assistencial destinada aos internos a partir de seu apreço e formação técnico-científica no alienismo francês (Conselho Regional de Psicologia de São Paulo (CRP-SP), s/d).

Em suas atuações clínicas e escritas científicas, Teixeira Brandão defendeu a laicização do hospital psiquiátrico, ainda muito tomado pelo discurso religioso nas terapêuticas, a autoridade médica como gestor institucional e a criação de legislações específicas sobre os alienados (Santiago, 2014). Munido destas concepções, ele foi eleito deputado federal, vindo a ocupar a relatoria da Comissão de Saúde, de onde a redação do projeto de lei, que se tornaria decreto, foi feita (CRP-SP, s/d; Santiago, 2014).

Analisamos que o decreto de autoria de Teixeira Brandão inaugurou um novo olhar sobre os adoecidos mentalmente. Até então, questões morais e religiosas ainda orientavam as terapêuticas. Com o decreto, o Estado foi chamado para um lugar intervencionista sobre a doença e o doente mental. No

8 Estudos Interdisciplinares em Psicologia, Londrina, v. 10, n. 3supl, p. 04-23, dez. 2019 
texto, havia diretrizes que colocavam o estabelecimento psiquiátrico (hospital, asilo ou casa de saúde) como espaço privilegiado da assistência (artigo 10.), desde que comprovada a alienação (artigo 10, § 10.) e autorizada a internação pela autoridade médica (artigo $2^{\circ}$.; artigo $13^{\circ}$., § $1^{\circ}$.).

Tais ditames eram coerentes com os preceitos científicos da época, ou seja, de um modelo assistencial hospitalocêntrico marcado pela segregação do doente, que retirado da sociedade cumpria um objetivo muito mais de proteção do coletivo do que do próprio indivíduo adoecido (Amarante, 2000), como textualmente indica o artigo 10.: "O individuo que, por molestia mental, congenita ou adquirida, comprometter a ordem publica ou a segurança das pessoas, será recolhido a um estabelecimento de alienados " (Decreto 1.132, 1903). Como o decreto definiu, o psiquiatra foi legitimado como o perito da loucura, ou seja, legalmente reconhecido e autorizado a produzir saberes científicos sobre a doença mental (Santiago, 2014).

Neste âmbito, a família foi colocada em duas posições no escrito legal: como possível requerente de internação em instituição asilar e como locus de espaço de assistência domiciliar. Apesar de tal presença, a perspectiva asilar que o decreto alimentou via o indivíduo como um ser doente "em si" independentemente de qualquer possível relação com o contexto social ou familiar, logo, a assistência familiar, quando possível, ocorreria a partir de ações pedagógicas ou terapêuticas (Costa-Rosa, 2000).

O resgate histórico do contexto brasileiro e de outros países, indicou a forma pela qual no interior dos hospitais psiquiátricos os pacientes foram distribuídos por setores a partir de características sociais, econômicas e, mesmo, étnicas. Os advindos de famílias tradicionais, geralmente com propriedades e influência social, ocupavam alojamentos particulares que eram os melhores na instituição, com quartos privados e confortáveis. Para os mais pobres, as enfermarias coletivas, as camas com amarrações para contenção e a restrição de trânsito interno, era o padrão (Amarante, 2000; Cunha, 1986; Foucault, 2014).

Do ponto de vista do poder psiquiátrico, acreditava-se que aqueles advindos de famílias com melhores condições de vida seriam mais propensos ao pleno restabelecimento mental, visto como a correção de um desajuste existencial outrora presente. Inclusive, as internações particulares registravam, mais comumente, períodos curtos de internação, com alta formal após algumas semanas ou meses. Os internos em leitos públicos, geralmente pobres, negros, indigentes e outros, permaneciam por anos sob a tutela do asilo (Cunha, 1986).

A despeito do investimento feito no tratamento daqueles considerados loucos, podia-se observar que os espaços destinados ao tratamento se configuravam mais como locais para a perda da sanidade do que para sua recuperação, devido às péssimas condições (Vasconcellos \& Vasconcellos, 2007). De forma similar, Cunha (1998), ao discorrer sobre a laborterapia empregada no Juquery, sinalizou que o trabalho era prescrito apenas àqueles que não pagavam 
pelo tratamento, entendendo-se que para os pagantes as propriedades curativas do trabalho eram excluídas. Neste sentido, havia uma divisão dos internos em pensionistas e indigentes, isto é, aqueles que, respectivamente, tinham ou não condições de pagar pela internação, de maneira que os tratamentos e modos de vida aos quais eram submetidos se diferenciavam, retratando as distinções entre as classes sociais (Cunha, 1998).

Tais dados evidenciaram que, apesar da centralidade da doença mental, naquele momento histórico o trato institucional impôs modelagens de condutas com o intuito de se atingir vidas normalizadas, ou seja, obedientes, moralmente dignas e socialmente produtivas. Cunha (1998) ilustrou tal concepção ao descrever o caso de Eunice, advinda de uma família que seguia os padrões demandados pelos alienistas, qual seja, amorosa e bem estruturada. A despeito de a família apresentar o padrão almejado contra a degenerescência, a mulher acabou por se dedicar, na visão da época, demasiadamente ao trabalho, tendo permanecido solteira, independente e sem aceitar intervenções do pai ou irmãos em suas escolhas pessoais, fatos que levaram à internação no Juquery em 1910, aos 30 anos. Sua saída da internação ocorreu após cinco meses, quando concordou em retornar à casa paterna e desempenhar o papel socialmente destinado às mulheres com seu perfil socioeconômico (Cunha, 1998). De tal forma, modos de ser distintos dos normalizados eram patologizados, instrumentalizando formas diversas de controle que reforçavam noções de vidas desviantes que seriam registradas em prontuários, relatórios e dossiês institucionais (Cunha, 1986; Foucault, 2014).

Alguns autores (Amarante, 2000; Castel, 1987; Foucault, 1999) discutiram como, historicamente, a instituição manicomial foi difusora de práticas de internação de indivíduos vulneráveis e com vidas consideradas moralmente infames e, em especial a partir do século XIX, de internações disciplinares. Neste cenário, a legalidade inaugurada pelo decreto de 1903 produziu como efeito a visibilidade jurídica e social de vidas degeneradas dos loucos por meio da obrigatoriedade de avaliações que atestariam a alienação, bem como, a necessidade de internação, que era por vezes sintomaticamente chamada de "detenção" no documento.

O principal agente propagador deste efeito de visibilidade era o alienista que, por ter a posse dos ditames sobre a doença mental, assumiu a posição de perito do poder normalizador, podendo avaliar, definir e guiar as intervenções cabíveis aos doentes mentais. No entanto, tal discurso evidenciou outras construções, ao se perceber que origem familiar e posição socioeconômica tornaram-se orientadores nas estratégias terapêuticas que foram adotadas.

\section{A emergência legal da assistência familiar}

No entanto, a partir deste primeiro documento que legalmente propôs uma psiquiatrização da loucura, o olhar para a assistência psiquiátrica brasileira 
sistematicamente exigiu amplitudes e aprofundamentos na constituição de outros e novos discursos que seriam localizados em alguns estados brasileiros, até que uma nova legislação federal se estabelecesse. O documento de 1903 foi revogado apenas trinta anos depois da aprovação, em julho de 1934, do Decreto 24.559 que dispôs sobre a profilaxia mental, a assistência e proteção à pessoa e aos bens dos loucos, a fiscalização dos serviços psiquiátricos, além de outras providências (Decreto 24.559, 1934).

No Brasil, a década de 1930 foi de movimentações sociais e políticas com, entre outras ocorrências, a Revolução Constitucionalista de 1932 e a promulgação de uma nova Constituição Federal, em substituição a de 1891 (Fausto, 2013). Tais efervescências contribuíram direta e indiretamente para a formulação da legislação de assistência psiquiátrica que mais tempo ficou em vigor no país, de 1934 até 1990.

Colocado sob lupas, o Decreto de 1934 nos permitiu fazer alguns destaques. Antes, porém, quanto ao uso que fez do termo "psicopata", cabe esclarecer que anos antes outro documento legal fez alterações no ordenamento jurídico acerca do indivíduo psicopata, compreendido como aquele com perturbação mental, mas sem comportamento antissocial, e o indivíduo alienado, visto como o doente mental perigoso, passível de ser civil e penalmente incapacitado de forma compulsória (Decreto 17.805, 1927).

Enquanto eixo central do texto jurídico estava a profilaxia mental, com seus desdobramentos alcançando ações de higiene social. Ampliou-se o escopo de características que indicavam comprometimentos mentais que tornavam necessária a terapêutica psiquiátrica. Os doentes mentais tiveram sua internação juridicamente facilitada pelo decreto, bem como aqueles ainda não doentes, mas vistos como potenciais enfermos, chamados no escrito de "indivíduos suspeitos", condição demarcada pela perturbação ou ofensa da ordem e moral pública (artigo 10, §10.), termos citados sem maiores esclarecimentos. Tornou-se flagrante a preocupação do Estado com a promoção do bem-estar social, o que exigiu a identificação de parcelas da população consideradas mais vulneráveis para serem orientadas e terapeuticamente guiadas para existências saudáveis e moralmente desejáveis.

No contexto social dos anos de 1930, em especial do início da Era Vargas, o Brasil viveu um período de marcado nacionalismo e ações de nacionalização dos indivíduos, muito deles estrangeiros que chegavam ao país fugindo dos movimentos nazifacistas europeus (Fausto, 2013). No campo da psiquiatria, aproximações com o pensamento alemão e algumas de suas inspirações eugênicas e higienistas pautadas em análises de aspectos étnicos, sociais e políticos, ganharam força e representatividade com a Liga Brasileira de Higiene Mental (LBHM). Fundada em 1923, teve significativa atuação ao longo da década de 1930 (Costa, 2007), inclusive, sendo textualmente citada na escrita jurídica 
de 1934 em que obteve o direito de assumir representação no Conselho de Proteção aos Psicopatas, instituído pelo documento.

Compreendemos que tais linhas de forças atuaram na composição do Decreto de 1934. A preocupação deste com o terreno social se traduziu pelo desenho das potencialidades do risco que a doença mental representava para a sociedade. No documento, o uso de termos como "indivíduos suspeitos" (artigo 70., § 10.), "contágio mental iminente" (artigo 220., §10.), "ofender a moral pública" (artigo 10.), entre outros, eram constantemente acompanhados por caracterizações dos comportamentos desviantes. Termos que constituíram evidências de que o vir a ser desviante tornou-se tão importante quanto o ser desviante. Tais terminologias fundamentaram justificativas para a reclusão, bem como a manutenção da doença mental. Neste sentido, Amarante (2000) nos lembrou que a "... medicina mental ratificou em sua definição de doença mental a equação doente mental-perigo social. Sendo assim, a definição jurídica não poderia deixar de reafirmar a sua presença." (p. 189).

Em comparativo com o documento anterior, neste, o núcleo familiar ganhou visibilidade: como possível solicitante de internação e alta de um paciente, e como reivindicação formal do lar como espaço capaz de suprir os cuidados psiquiátricos. A implicação da família do indivíduo adoecido em seu processo de assistência e cuidado ainda não tinha historicamente sido tão bem demarcada. No entanto, o olhar mais atento para a letra jurídica evidenciou a incongruência do discurso de normalização. O encaminhamento das solicitações deveria ocorrer por uma figura familiar masculina: cônjuge, pai ou filho (artigo 110.). Como Cunha (1986) já nos alertou, se o louco era silenciado pela segregação do manicômio, a mulher mentalmente adoecida era calada duplamente, pela instituição asilar e pela legislação.

Cunha (1998) ilustrou essa situação ao apresentar casos de mulheres internadas no Juquery. Se por um lado a independência feminina poderia não ser aceita pela família gerando a internação psiquiátrica como no caso de Eunice, acima apresentado, por outro, o casamento deveria ocorrer com a concordância paterna, algo não aceito pelo pai de Lavínia, outra paciente retratada pela autora, que buscou a internação com o intuito de impedir o casamento desejado pela filha, algo aceito pelo alienista apesar das deduções diagnósticas inconclusivas.

Considerando que as relações entre loucura e a mulher se apresentam como algo complexo, Vasconcellos e Vasconcellos (2007) buscaram, por meio de um estudo documental referente ao período de 1870 a 1910, investigar como as mulheres consideradas loucas eram identificadas e tratadas na região de Porto Alegre-RS. Tais autores indicaram que, a despeito de haver uma proporcionalidade entre homens e mulheres internados no Hospício São Pedro, havia dois enfermeiros homens e apenas uma enfermeira mulher, cujo salário era inferior ao recebido pela categoria masculina, mesmo considerando que "a 
doente dava maior trabalho" (p. 1044). Acerca dos motivos que geraram a internação, discorreram sobre situações relativas ao ser mulher, tais como a gravidez, o puerpério, a perda ou sofrimento de filhos, como o estupro de uma filha, diferentemente dos homens, quando "a ruína nos negócios era um motivo justificado para o seu enlouquecimento" (Vasconcellos \& Vasconcellos, 2007, p. 1046). Adicionalmente, apontaram que às mulheres abastadas estava reservado o papel de esposa e mãe, enquanto que as mulheres da classe trabalhadora usualmente assumiam a função de provedoras.

Pensando nas alterações do papel da mulher na sociedade, que passou a ocupar não apenas o status de esposa e mãe, mas também de trabalhadora, implicando em mudanças nas relações de gênero, Gastal et al. (2006) delinearam um perfil da clientela feminina de um serviço de internação psiquiátrica de Pelotas-RS entre os anos de 1931 a 2000. Notaram que houve um predomínio de mulheres brancas (91,3\%), entre 26 a 45 anos (47,9\%). Inicialmente havia um número maior de mulheres casadas (44,9\%) em comparação com as solteiras (35,31\%), com essa proporção se invertendo entre os anos 1991-2000, com gradual aumento do número de mulheres separadas. No que se refere aos setores profissionais, notaram maior concentração de mulheres fora da população economicamente ativa, especialmente entre os anos 1930 e 1960 (96,71\%). Na década de 1970, 20,12\% das mulheres internadas eram advindas de grupos sociais ligados ao setor industrial, com esse valor diminuindo nos anos seguintes em decorrência do fechamento de indústrias na região, fato que implicou na diminuição do número de mulheres da própria região nesse setor industrial. Quanto à nosologia, perceberam que os transtornos afetivos e as psicoses esquizofrênicas foram responsáveis pelo maior número de internações, $28,6 \%$ e $25,2 \%$ respectivamente. Se por um lado os resultados relacionam-se a aspectos da realidade local, tal como a concentração de mulheres brancas e fora da população economicamente ativa, por outro, argumentam que "As manifestações de doença [...] podem estar a confirmar o aumento das tensões psicossociais e as cargas de trabalho sobre as mulheres" (Gastal et al., 2006, p. 252).

Ainda sobre as relações de gênero no cenário da saúde mental, tem-se o trabalho de Santos (2009) que discutiu a temática tendo em vista as mudanças no sistema psiquiátrico brasileiro advindas da luta antimanicomial. Por meio de entrevistas com usuários de um Centro de Atenção Psicossocial, observou uma correlação entre o adoecimento psíquico e a violência contra as mulheres, com relatos de agressões físicas e psicológicas dos ex-cônjuges, além de sinalizar a influência das normas sociais no exercício da sexualidade feminina. As mulheres se apresentaram, ademais, como as cuidadoras encarregadas do cuidado extrahospitalar tanto dos homens quanto das mulheres, sendo que mesmo estando doente as mulheres com filhos acabavam por também exercer a tarefa de cuidado de sua prole. 
Sobre o tema, tem-se o trabalho de Pegoraro e Caldana (2008) que revisaram a condição da mulher no cuidado em saúde mental e notaram que, ao longo do tempo, a figura feminina se mostrou como a responsável pelo cuidado em saúde mental. Argumentaram que, diante desse quadro, é necessário, no caso de mulheres com filhos, que "as equipes forneçam suporte às famílias cujas mulheres apresentam quadros graves" (p. 92), entendendo a mulher não apenas como informante e cuidadora, mas como alguém que necessitava de intervenção profissional.

Retornando à questão da família de forma mais ampla, concebemos que a ideia do espaço familiar como propenso a suprir as necessidades de assistência psiquiátrica é congruente com os ditames psiquiátricos mais amplos da época, como a estratégia chamada de Assistência Familiar. Ela é definida como sendo a assistência psiquiátrica conduzida por familiares do paciente a fim de promoverem um retorno terapêutico para a sociedade. Em caso de ser esta a família biológica, denominava-se de assistência homo-familiar e, em caso de famílias "substitutivas", assistência hetero-familiar. Em ambas as modalidades, a instrumentalização e acompanhamento do psiquiatra e de uma equipe de saúde, eram os esforços para garantir a eficiência no processo (Rezende, 1931).

Os serviços de hetero-família eram constituídos por famílias de empregados do manicômio transferidas para casas localizadas no entorno da instituição asilar. Nestas casas, as famílias artificiais recebiam os internos para serem responsáveis pela promoção de um regresso gradual para o meio social por meio do incentivo da expressão de afeto, incentivo à produtividade e do treino para a vida normal (Rezende, 1931). Desta forma, a hetero-família era uma etapa intermediária entre a vida segregada e a existência adoecida no manicômio e a vida livre e normal em meio aberto. Tal terapêutica seria responsável por melhoras significativas em indivíduos com determinadas condições, como alguns tipos de esquizofrenia, como destaca Rezende (1931).

Neste contexto, a família assumiu função terapêutica e (re)potencializadora das habilidades sociais dos doentes por meio de seus laços e expressões de afetividade, bem como do treino de disciplinamento e vigilância de hábitos alimentares, higiene, comportamentos morais e de bons costumes. Foi a partir destes delineamentos que a assistência familiar emergiu no decreto de 1934. Notou-se que as linhas de força para as quais a assistência familiar contribuiu trouxe a noção de família articulada de forma estratégica para as formulações de respostas aos chamados normalizadores, ou seja, de um ser e viver a partir de parâmetros e prescrições que colocavam o indivíduo adoecido mentalmente na norma social dominante. Como pontuaram Souza et al. (2002), o olhar atribuído à família no contexto da atenção psiquiátrica se modificou ao longo do tempo, com base no argumento de que ela acabava por ser considerada como um recurso, por se configurar como um "alicerce" ou uma "rede terapêutica" para a pessoa em tratamento. 
Apesar da solicitação jurídica e abertura factual de envolvimento do núcleo familiar no processo de assistência ao ente, esta participação era disciplinada por diretrizes de treino para a vida normal a partir da bagagem moral que as famílias (consanguíneas ou artificiais) tinham condições de promover (Santiago, 2014). Torna-se importante destacar que o núcleo familiar compreendido como passível de promover tais aspectos era da família burguesa, nuclear, com corolários de amor natural, em especial o materno, preceitos morais e religiosos elevados, ou seja, aquilo que era visto como um lar higiênico e socialmente aprovado.

Em artigo científico específico sobre tal assistência, Juliano Moreira, figura psiquiátrica proeminente naquele momento, dá suporte para nossa compreensão:

Para uma porção bastante consideravel de alienados carecendo de assistencia e que podem ser submettidos a esse tratamento, a assistencia familiar representa a fórma mais natural, mais livre, a melhor [...], além disso, para um grande numero delles um factor therapeutico importante (Santiago, 2014, p. 106 apud Moreira, 1906, p. 28).

Os serviços de assistência familiar se constituíram como uma forma simplificada das instituições chamadas de Colônias de Alienados ou Hospitais Colônias, que teriam reconhecida importância nos processos de tutela e tratamento dos doentes mentais (Amarante, 2007; Costa, 2007). No Brasil, a principal representante deste modelo foi a Colônia do Juquery. Fundada em 1924, nos anos de 1940 e 1950, chegou a ter 16 mil internos ao mesmo tempo (Amarante, 2007), demonstrando a confiança da psiquiatria nacional quanto à terapêutica desenvolvida que foi contribuinte para transformações na arquitetura física dos manicômios.

\section{Desafios no cuidado em liberdade}

Nas décadas seguintes, experiências reformadoras da assistência psiquiátrica e da própria psiquiatria ganharam força na Europa e Estados Unidos, sendo acompanhadas por discussões desinstitucionalizantes. No Brasil, a expansão da rede de assistência à saúde e em saúde mental ocorreu pela compra do Governo Federal, de serviços, procedimentos e leitos privados. Durante a ditadura militar, a assistência psiquiátrica ganhou uma organização privatista e industrial, com denúncias quanto às internações longas, debilitantes e de preponderância medicamentosa que teve como foco a lucratividade do sistema e não o tratamento dos internos, constituindo o que ficou conhecida como indústria da loucura (Amarante, 2000).

Do ponto de vista dos discursos políticos, cinco Conferências Nacionais de Saúde ocorreram entre as décadas de 1960 e 1980 e disponibilizaram espaços para discussões sobre a saúde pública brasileira e o encaminhamento de proposições e diretrizes para políticas públicas. Em meio a estas mobilizações, destacaram-se o Movimento da Luta Antimanicomial e o Movimento da Reforma 
Psiquiátrica, iniciados no fim da década de 1970. Em uma das Conferências citadas, a de 1986, seu relatório final serviu de subsídio para a constituição do artigo sobre saúde na Carta Constitucional de 1988 e, mais tarde ainda, para a instauração do Sistema Único de Saúde (SUS), em 1990 (Amarante, 2000; 2007).

A sociedade brasileira viveu anos de efervescência social e política que mobilizaram temas, atores e arenas de movimentos diversos. Neste ensejo, tornou-se temática constante de discussões a cidadania dos adoecidos mentalmente, pauta impulsionada pelo Movimento dos Trabalhadores em Saúde Mental (MTSM). Criado em 1978, este coletivo aglutinou profissionais, pacientes e familiares de pacientes e outros setores da sociedade produzindo críticas às práticas psiquiátricas então vigentes com reivindicações para a construção de outro olhar para a loucura em uma sociedade sem manicômios.

Amarante e Torre (2001) afirmaram que, a partir da segunda metade dos anos de 1980, transformações no campo da saúde mental fomentaram a criação de novos serviços e novas práxis em um "[...] contexto histórico, político e conceitual emergente [...] (o que abriu) novos caminhos para a saúde pública no Brasil da 'redemocratização'". (p. 27). Os autores destacaram a criação do primeiro CAPS brasileiro em março de 1987, em São Paulo capital, e do primeiro Núcleo de Atenção Psicossocial (NAPS) na cidade de Santos-SP, após a histórica intervenção e fechamento da Casa Anchieta em 1989 nesta cidade (Amarante \& Torre, 2001).

No âmbito da discussão legal, produções estaduais instituíram revisões na assistência em saúde mental: em Pernambuco, em 1994, no Paraná, em 1995, em Minas Gerais, em 1997 (Santiago, 2014). Na instância federal, a Lei n. 10.216/2001, que dispôs sobre a proteção e os direitos das pessoas com transtornos mentais, incluiu princípios fundamentais de direitos humanos e redirecionou o modelo assistencial em saúde mental para uma lógica nãomanicomial (Lei 10.216, 2001), estabelecendo uma revisão significativa na legislação vindo a ficar conhecida como Lei da Reforma Psiquiátrica. Tal lei, em conjunto com o SUS, constituiu a Política Nacional de Saúde Mental, em vigor até os dias de hoje.

A tramitação do projeto até a aprovação da Lei 10.216, em 2001, foi longa, perfazendo cerca de dez anos. De autoria de Paulo Delgado, parlamentar com formação em ciências sociais e ciência política, a tramitação do texto foi cercada de embates, evidenciando o jogo de forças entre a manutenção do modelo vigente de assistência em doença mental e o protótipo de uma outra compreensão sobre a saúde mental e seus reflexos no discurso jurídico (Santiago, 2014). De forma definitiva, a partir da Lei de 2001, a legislação e a política pública discursam, com solicitude, sobre a existência e a subjetividade daqueles em sofrimento psíquico intenso e em situação de crise, vistos, a partir de então, como sujeitos de direitos. 
Em suas proposições, o documento de 2001 orientou sobre como o cuidado em saúde mental deveria ocorrer, prioritariamente, em contexto de liberdade, comunitário, diversificado e multidisciplinar, com vistas à reabilitação e à reinserção psicossocial. Nos anos seguintes, portarias ministeriais foram guias nestes processos ao instaurar políticas específicas com modalidades assistenciais substitutivas à centralidade hospitalar. São exemplos os Serviços Residenciais Terapêuticos (SRT), espaços de moradia para pacientes sem suporte familiar ou social e com histórico de longa permanência em hospitais psiquiátricos, e os Centros de Convivência e Cultura, dispositivos de apoio terapêutico e social por meio da produção cultural e intervenção na cidade (Ministério da Saúde, 2016).

Ao voltar-se para a vida e o convívio fora dos muros do manicômio, o texto jurídico reconheceu e priorizou os contextos sociais e comunitários como dimensões do processo de cuidado em saúde mental. Dentre estes, estava a família. Tem-se um reconhecimento dos laços familiares, que foram vistos como parte dos processos de reabilitação e reinserção psicossocial. Para isso, a aproximação familiar e o restabelecimento dos vínculos do sujeito adoecido com este núcleo tornou-se um direito legalmente fundamentado na Lei 10.216/2001 (parágrafo único, $\S 2^{\circ}$ ). Neste sentido, o cuidado ao sujeito em sofrimento psíquico intenso pressupôs que a família e a sociedade sejam ativas no processo (artigo $3^{\circ}$.) em um cuidar prioritariamente em liberdade.

Costa-Rosa (2000) apontou sobre a necessidade de preparar família e sociedade para este novo papel de agentes da mudança buscada. Entretanto, a inclusão destes atores evidenciou o ineditismo da perspectiva de que "[...] a loucura não é um fenômeno exclusivamente individual, mas social e como tal deverá ser metabolizada." (p. 154).

Os espaços de chamamentos para a implicação familiar no processo de cuidado tornaram-se muitos a partir da legislação de 2001 e multiplicaram-se em políticas públicas. A presença historicamente importante de familiares no MTSM antecedeu o próprio texto jurídico, desdobrando-se nas associações de usuários e familiares, com superação das posturas assistenciais e orientadoras (CostaRosa, 2000). Programas e ações diversificadas constituíram-se como vozes para este chamamento tal como o programa "De volta para casa", criado em 2003, que se dedicou a, além de outros pontos, trabalhar a retomada com as famílias de origem, famílias substitutivas e laços afetivos com grupos ampliados, dos pacientes de longa permanência em hospitais psiquiátricos (Ministério da Saúde, 2016), o que evidenciou a importância dos vínculos afetivos, biológicos ou não, no cuidado em saúde mental e na reinserção social.

Dentre os dispositivos atuantes nas diretrizes da atenção em liberdade, o CAPS tornou-se o ordenador do cuidado de necessidades decorrentes do sofrimento psíquico, articulador da rede de atenção em saúde mental no território e principal efetivador da desinstitucionalização (Ministério da Saúde, 
2016). Criado antes da Lei 10.216/2001, em 1986, o CAPS recebeu normatizações do Ministério da Saúde nas décadas seguintes, expandindo-se para centenas de unidades em diferentes modalidades conforme o tamanho dos municípios brasileiros. Dentre as modalidades ofertadas pelos CAPS de fortalecimento e protagonismo familiar do sujeito em sofrimento psíquico estão espaços intra e extra dispositivo, de caráter psicoterapêutico, psicoeducativo e vivencial-expressivo em atendimentos individuais, grupais e familiares, além de outras possíveis ações e projetos diversos (Ministério da Saúde, 2016).

A inclusão da família na atenção e o suporte ao sujeito em sofrimento psíquico intenso foram jurídica e historicamente diferenciados ao se guiar pelo paradigma da desinstitucionalização. Ao exigir reposicionamento e implicação subjetivos e objetivos do núcleo familiar no processo do cuidado, evidenciou-se que a legislação e as políticas públicas valorizaram os laços afetivos na promoção da atenção em saúde e em saúde mental e reconheceu-se a família como importante elemento para a consolidação da desinstitucionalização e do processo de Reforma Psiquiátrica brasileira (Gonçalves \& Sena, 2001).

Entretanto, a participação efetiva da família tornou-se um desafio na vivência concreta do cuidado cotidiano, como apontaram alguns estudos recentes a partir da escuta dos próprios familiares (Oliveira et al., 2016; Martins \& Guanaes-Lorenzo, 2016). Tal fato se configura como uma questão ainda a ser enfrentada, mas que foge do escopo desta discussão.

Em fechamento desta discussão, frisamos que a participação de familiares de pacientes e usuários foi um destaque na história da política de atenção em saúde mental. Nos últimos meses, estes têm voltado a se mobilizar, em união de forças, junto às organizações e movimentos sociais fazendo denúncias sobre a elaboração e aprovação de políticas que indicariam novas diretrizes de assistência e cuidado na área de saúde e saúde mental com a inserção do hospital psiquiátrico no centro da rede de atenção psicossocial, restrição de investimentos no SUS, aumento de repasses financeiros e compra de serviços na rede privada de assistência psiquiátrica com lógica pautada na reclusão (Conselho Federal de Psicologia - CFP, 2019; Conselho Nacional de Saúde, 2019).

As manifestações são quanto aos riscos do desmonte da Política Nacional de Saúde Mental, com retrocessos no que diz respeito aos direitos conquistados por meio da lei 10.216/2001. Tais discursos jurídicos são lidos pelos coletivos como grave despersonalização do cuidado em liberdade, que ferem os princípios da reforma psiquiátrica (CFP, 2019).

\section{CONSIDERAÇÕES FINAIS}

A jornada aqui feita sobre a família na história da saúde mental, a partir de documentos, nos permitiu discutir as formas pelas quais a legislação brasileira 
se apropriou da loucura, bem como daqueles em sofrimento psíquico. A noção de família está presente nesta história mas, a partir de nosso entendimento, ocupou posições e funções jurídicas e terapêuticas distintas, refletindo, ao mesmo tempo em que é reflexo, as configurações de família consideradas conceitualmente legítimas em cada momento.

Assim, a partir da trajetória traçada e das problematizações feitas, podemos afirmar que o chamado e a presença da família na assistência e no cuidado com o sujeito em sofrimento psíquico intenso assumiram formas coincidentes ou aproximadas com as transformações que a própria instituição familiar vivenciou nas últimas décadas, algo também sinalizado por outros autores.

No percurso deste artigo, observamos que, no primeiro texto jurídico brasileiro que tratou do adoecimento mental, o vínculo formalizado de família foi a única possibilidade considerada válida. Os laços biológicos ou de casamento foram os elementos demarcadores do núcleo familiar. No segundo documento, o vínculo afetivo, junto ao legal e ao biológico, ganhou reconhecimento jurídico em sua potencialidade de articular relações de significativa proximidade e de acolhimento e suporte para aqueles em sofrimento psíquico neste grupo, condições que poderiam ser atravessadas por aspectos de gênero, étnico ou socioeconômico. Em um terceiro documento, mais recente, os laços afetivos ganharam preponderância, com uma diferente proposição na legislação acerca daquilo que pode ser compreendido como família.

Concluímos sustentando que as reflexões aqui apresentadas podem servir como subsídio para o trabalho de técnicos, profissionais, pesquisadores e gestores na produção de novos conhecimentos e formas de atenção no campo da atenção em saúde mental, assim como, novas políticas que considerem e incluam, em sua conceituação atual, os familiares dos sujeitos em sofrimento psíquico intenso. Além disso, a conjuntura atual na área da saúde e saúde mental aponta pata mudanças e desdobramentos, demandando a constituição de novas agendas de pesquisas que ajudem a constituir uma leitura do presente, algo que pode ser favorecido a partir da compreensão de percursos históricos como o aqui realizado.

\section{DECLARAÇÃO DE CONFLITOS DE INTERESSE}

A primeira autora é também editora da Revista Estudos Interdisciplinares em Psicologia. A segunda autora não declara conflitos de interesses.

\section{REFERÊNCIAS}

Amarante, P. (2000). Loucos pela vida: a trajetória da reforma psiquiátrica no Brasil. Rio de Janeiro: Panorama/ENSP. 
Amarante, P. (2007). Saúde mental e atenção psicossocial. 2. ed. Rio de Janeiro: Editora Fiocruz.

Amarante, P. \& Torre, E. H. G. (2001). A constituição de novas práticas no campo da Atenção Psicossocial: análise de dois projetos pioneiros na Reforma Psiquiátrica no Brasil. Saúde em debate, 25(58), 26-34. Recuperado em 25 de maio de 2019, de http://docvirt.com/asp/acervo_cebes.asp?Bib=SAUDEDEBATE\&PASTA=V .25 $\% 2 \mathrm{C}+\mathrm{N} .58+-+$ maio\&pesq $=\& \mathrm{x}=43 \& \mathrm{y}=4$.

Berenstein, I. (1988). Família e doença mental. São Paulo: Escuta.

Castel, R. (1987). A gestão dos riscos: da antipsiquiatria à pós-psicanálise. Rio de Janeiro: Ed. Francisco Alves.

Conselho Regional de Psicologia de São Paulo (CRP-SP). (s/d). Linha do tempo: verbetes. Recuperado em 20 de maio de 2019, de http://www.crpsp.org.br/linha/verbetes.aspx.

Conselho Federal de Psicologia (CFP). (2019, 08 de fevereiro). CFP manifesta repúdio à nota técnica "Nova Saúde Mental" publicada pelo Ministério da Saúde. Notícias. Recuperado em 10 de junho de 2019, de https://site.cfp.org.br/cfp-manifesta-repudio-a-nota-tecnica-nova-saudemental-publicada-pelo-ministerio-da-saude/.

Conselho Nacional de Saúde (CNS). (2019, 06 de junho). Resistência e democracia marcam abertura do $10^{\circ}$ Congresso Nacional de Psicologia. Notícias. Recuperado em 10 de junho de 2019, de http://conselho.saude.gov.br/ultimas-noticias-cns/622-resistencia-edefesa-da-democracia-marcam-abertura-do-10-congresso-nacional-depsicologia.

Costa, J. F. (2007). História da psiquiatria no Brasil: um corte ideológico. Rio de Janeiro: Garamoud.

Costa-Rosa, A. (2000). O modo psicossocial: um paradigma das práticas substitutivas ao modo asilar. In P. Amarante (Org.), Ensaios: subjetividade, saúde mental e sociedade (pp. 141-168). Rio de Janeiro: Fiocruz. Recuperado em 20 de maio de 2019, de http://books.scielo.org/id/htjgj/pdf/amarante-9788575413197-09.pdf.

Cunha, M. C. P. (1986). O espelho do mundo: Juquery, a história de um asilo. Rio de Janeiro: Editora Paz e Terra.

Cunha, M. C. P. (1998). De historiadoras, brasileiras e escandinavas: loucuras, folias e relações de gêneros no Brasil (século XIX e início do XX). Tempo, 3(5), 181-215. Recuperado em 10 de junho de 2019, de http://www.historia.uff.br/tempo/artigos_livres/artg5-9.pdf.

Decreto n. 1.132, de 22 de Dezembro de 1903. (1903). Lei de assistência aos alienados. Recuperado em 20 de maio de 2019, de http://www2.camara.gov.br/legin/fed/decret/1900-1909/decreto-1132-22dezembro-1903-585004-publicacaooriginal-107902-pl.html. 
Decreto n. 17.805, de 23 de Maio de 1927. (1927). Approva o regulamento para execução dos serviços da Assistencia a Psychopathas no Districto Federal. Recuperado em 20 de maio de 2019, de http://www2.camara.leg.br/legin/fed/decret/1920-1929/decreto-17805-23maio-1927-49907 3 -publicacaooriginal-1-pe.html.

Decreto n. 24.559, de 3 de Julho de 1934. (1934). Dispõe sôbre a profilaxia mental, a assistência e proteção á pessôa e aos bens dos psicopatas, a fiscalização dos serviços psiquiátricos e dá outras providências. Recuperado em 22 de maio de 2019, de https://www2.camara.leg.br/legin/fed/decret/1930-1939/decreto-24559-3julho-1934-515889-publicacaooriginal-1-pe.html.

Fausto, B. (2013). História do Brasil. São Paulo: Edusp.

Foucault, M. (1999). A verdade e as formas jurídicas. Rio de Janeiro: Nau.

Foucault, M. (2014). História da loucura. 10a ed. São Paulo: Perspectiva.

Gastal, F. L., Leite, S. S. O., Treptow, E. C., Marini, S. S., Noal, M. V., Binz, M. A. R., \& Amaral, M. T. (2006). Doença mental, mulheres e transformação social: um perfil evolutivo institucional de 1931 a 2000. Revista de Psiquiatria do Rio Grande do Sul, 28(3), 245-254. https://dx.doi.org/10.1590/S0101-81082006000300004

Gonçalves, A. M., \& Sena, R. R. (2001). A reforma psiquiátrica no Brasil: contextualização e reflexos sobre o cuidado com o doente mental na família. Revista Latino-americana de Enfermagem, 9(2), 48-55. http://dx.doi.org/10.1590/S0104-11692001000200007

Lei n. 8.080, de 19 de setembro de 1990. (1990). Dispõe sobre as condições para a promoção, proteção e recuperação da saúde, a organização e o funcionamento dos serviços correspondentes e dá outras providências. Recuperado em 24 de maio de 2019, de http://www.planalto.gov.br/ccivil_03/leis/l8080.htm.

Lei n. 10.216, de 06 de abril de 2001. (2001). Dispõe sobre a proteção e os direitos das pessoas portadoras de transtornos mentais e redireciona o modelo assistencial em saúde mental. Recuperado em 22 de maio de 2019, de http://www.planalto.gov.br/ccivil03/leis/leis2001/l10216.htm

Martins, P. P. S., \& Guanaes-Lorenzi, C. (2016). Participação da Família no Tratamento em Saúde Mental como Prática no Cotidiano do Serviço. Psicologia: teoria e pesquisa, 32(4), 1-9. https://dx.doi.org/10.1590/0102.3772e324216

Meyer, L. (2002). Família: dinâmica e terapia. Uma abordagem psicanalítica. 2a. ed revisada e atualizada. São Paulo: Casa do Psicólogo. 
Ministério da Saúde, Secretaria de Atenção à Saúde, Departamento de Ações Programáticas Estratégicas, Coordenação Geral de Saúde Mental, Álcool e Outras Drogas. (2016). Saúde Mental no SUS: Cuidado em Liberdade, Defesa de Direitos e Rede de Atenção Psicossocial. Relatório de Gestão 2011-2015. Ministério da Saúde: Brasília. Recuperado em 27 de maio de 2019, de

http://portalarquivos2.saude.gov.br/images/pdf/2016/junho/27/Relat--rioGest--o-2011-2015---.pdf.

Pegoraro, R. F. (2009). Papéis atribuídos à família na produção da loucura: algumas reflexões. Boletim - Academia Paulista de Psicologia, 29(2), 253273. Recuperado em 05 de junho de 2019, de http://pepsic.bvsalud.org/scielo.php?script=sci_arttext\&pid=S1415-

$711 \times 2009000200004 \&$ Ing $=p t \& t$ Ing $=p t$.

Pegoraro, R. F., \& Caldana, R. H. L. (2008). Mulheres, loucura e cuidado: a condição da mulher na provisão e demanda por cuidados em saúde mental. Saúde e Sociedade, 17(2), 82-94. https://dx.doi.org/10.1590/S010412902008000200009

Pontes, M. F., Féres-Carneiro, T., \& Magalhães, A. S. (2015). Famílias homoparentais e maternidade biológica. Psicologia \& Sociedade, 27(1), 189-198. https://dx.doi.org/10.1590/1807-03102015v27n1p189

Rezende, G. A. (1932). Assistencia hetero-familiar na Colonia de Psicopatas (mulheres) no Engenho de Dentro. In: W. Pires, \& Helim (Orgs), Anais da assistencia a psicopatas: Distrito Federal (pp. 133-139). Rio de Janeiro: Imprensa Nacional. Recuperado em 23 de maio de 2019, de http://bvsms.saude.gov.br/bvs/publicacoes/cd05_03.pdf

Rolnik, S. (2006). Cartografia sentimental: transformações contemporâneas do desejo. São Paulo: Sulina.

Roudinesco, E. (2003). A família em desordem. Rio de Janeiro: Jorge Zahar Ed.

Santiago, E. S. (2014). O trabalho como estratégia de atenção em saúde mental: cartografias do conceito trabalho nas políticas públicas de saúde. (Tese de Doutorado). Faculdade de Ciências e Letras, Universidade Estadual Paulista. Assis, SP, Brasil.

Santin, G., \& Klafke, T. E. (2011). A família e o cuidado em saúde mental. Barbaroi, (34), 146-160. Recuperado em 05 de junho de 2019, de https://online.unisc.br/seer/index.php/barbaroi/article/view/1643/1567.

Santos, A. M. C. C. (2009). Articular saúde mental e relações de gênero: dar voz aos sujeitos silenciados. Ciência \& Saúde Coletiva, 14(4), 1177-1182. https://dx.doi.org/10.1590/S1413-81232009000400023 
Silva, I. M., \& Frizzo, G. B. (2014). Ter ou não ter?: Uma revisão da literatura sobre casais sem filhos por opção. Pensando famílias, 18(2), 48-61. Recuperado em 10 de junho de 2019, de http://pepsic.bvsalud.org/scielo.php?script=sci_arttext\&pid=S1679494X2014000200005\&lng=pt\&tlng=pt.

Silva, J. A., Sousa, A. M. B. D., \& Fernandes-Eloi, J. (2017). Homoparentalidade no contexto da adoção e das práticas parentais: uma revisão sistemática. Pensando famílias, 21(2), 60-75. Recuperado em 10 de junho de 2019, de http://pepsic.bvsalud.org/scielo.php?script=sci_arttext\&pid=S1679494X2017000200006\&lng=pt\&tIng=pt.

Souza, R. C., Pereira, M. A. O., \& Scatena, M. C. M. (2002). Família e transformação da atenção psiquiátrica: olhares que se (des)encontram. Revista Gaúcha de Enfermagem, 23(2), 68-80. Recuperado em 05 de junho de 2019,

https://www.seer.ufrgs.br/RevistaGauchadeEnfermagem/article/view/4449/ 2374.

Vasconcellos, C. T. D. V., \& Vasconcellos, S. J. L. (2007). A doença mental feminina em Porto Alegre, Rio Grande do Sul, Brasil (1870-1910). Cadernos de Saúde Pública, 23(5), 1041-1049. https://dx.doi.org/10.1590/S0102$311 \times 2007000500006$

Waidman, M. A. P., \& Elsen, I. (2006). Os caminhos para cuidar da família no paradigma da desinstitucionalização: da utopia à realidade. Ciência, cuidado e Saúde, 5(supl.),

107-112.

http://dx.doi.org/10.4025/cienccuidsaude.v5i0.5174

Sobre os autores

Maíra Bonafé Sei é psicóloga pela Faculdade de Filosofia, Ciências e Letras da Universidade de São Paulo (USP), com mestrado, doutorado e pós-doutorado em Psicologia Clínica pelo Instituto de Psicologia da USP. Trabalha no Departamento de Psicologia e Psicanálise da Universidade Estadual de Londrina.

mairabonafe@gmail.com

Eneida Santiago é psicóloga pela Universidade Estadual Paulista (Unesp-Assis), mestre e doutora em Saúde Coletiva pela Universidade Estadual Paulista (UnespAssis). Trabalha no Departamento de Psicologia Social e Institucional da Universidade Estadual de Londrina. E-mail: esantiago@uel.br

A contribuição de cada autor pode ser atribuída como se segue: M.B.S. e E.S. contribuíram igualmente para a conceitualização, investigação e redação do artigo.

Recebido em: 10/06/2019

Revisado em: 18/10/2019

Aceito em: 19/12/2019 